\title{
BED EXPANSION CHARACTERISTICS IN MICROJET AND VIBRATION ASSISTED FLUIDIZATION OF $\mathrm{TIO}_{2}$ NANOPARTICLES
}

\author{
KEJU $\mathrm{AN}^{1} \&$ JEAN M. ANDINO ${ }^{2,3}$ \\ ${ }^{1}$ Mechanical Engineering, Arizona State University, USA \\ ${ }^{2}$ Chemical Engineering, Arizona State University, USA \\ ${ }^{3}$ Civil, Environmental and Sustainable Engineering, Arizona State University, USA
}

\begin{abstract}
A microjet and vibration assisted (MVA) fluidized bed was designed and tested to improve the fluidization quality of nanosized particles. Previous work relied on the addition of alcohol support in order to minimize electrostatic forces, thereby improving fluidization. The MVA method increased the fluidized bed height smoothly without the need for alcohol support. Thus, the MVA system is more versatile for use where the addition of a chemical may impact the process (e.g. environmental remediation). Commercial, nanosized $\mathrm{TiO}_{2}$ particles ( $\mathrm{P} 25$ from Evonik Degussa) were analyzed in the MVA system. It was operated at its resonance frequency $(50 \mathrm{~Hz})$, under different vibrational amplitude levels. The microjet was operated using a flow of nitrogen at 135.8, 170.3, 204.7, 239.2, 273.7 and $308.2 \mathrm{kPa}$ resulting in a downward stream through the micronozzle $(500 \mu \mathrm{m})$. The additional vibrational support enabled nanoparticle fluidization under lower inlet pressure and velocity conditions compared to systems where only a microjet was used. In the MVA system, the micronozzle velocity coupled with a vibrational intensity of 1.6 showed 5 times higher fluidized bed height compared to the packed bed. Optimal operating/processing conditions of the MVA system are suggested based on the experimental results. The results presented provide valuable parameters to develop computer simulations of large commercial and pilot scale fluidized bed systems.
\end{abstract}

Keywords: fluidization, nondimensional-height, microjet, vibration.

\section{INTRODUCTION}

The fluidization of nanoparticles in a gas has been broadly used in various industrial applications due to its exceptional ability of continuous mixing, large gas-solid contact surface area per unit mass, and high heat and mass transfer rate. Nanosized particles spontaneously lead to the formation of large agglomerates due to the large interparticle forces. Particularly with agglomerate bubbling fluidization (ABF) types of particles like $\mathrm{TiO}_{2}$ P25, fluidization is described by highly restricted bed expansion and large bubble formation when only using the superficial velocity to fluidize the particles [1] This is the reason why previous researchers applied assistance methods such as vibration or a microjet to obtain smooth fluidization behavior [2]-[4].

We have studied the behaviour of $\mathrm{TiO}_{2}$ nanoparticles in a microjet and vibration assisted (MVA) fluidized bed. This new experimental method aims to enhance the fluidization process in the absence of alcohol support. The nondimensional bed height was measured as a parameter of fluidization quality and the Richardson and Zaki's model [5] is used to examine the advantages of the MVA system. The theoretical Richardson and Zaki equation may be used to characterize the fluid-like regime that exists when gas is used to fluidize nanoparticles. By plotting the void fraction against the superficial gas velocity in the Richardson and Zaki form, the value of the exponent, n, which is a measure of bed expansion, can be determined. 
This work compares the MVA system to a vibrating fluidized bed (VFB) to show the advantages. Ultimately, the goal is to use the results of the current work to enhance the design of a photocatalytic chemical reactor for environmental remediation purposes.

\section{EXPERIMENTAL SETUP}

The experiments were performed in a circular column reactor made of clear cast acrylic with an internal diameter of $7.62 \mathrm{~cm}$ and a height of $1 \mathrm{~m}$. The bottom part of the reactor consists of a gas distributor which is a sintered, $2 \mathrm{~mm}$ thick quartz plate having a pore size of 20 microns with $40 \%$ opening area. The nitrogen leaving the compressed gas cylinder passed through a water bubbler that connected to the gas distributor at the bottom of the reactor. The exhaust gas through the reactor was filtered by a HEPA filter to remove any elutriated nanoparticles as shown in Fig. 1.

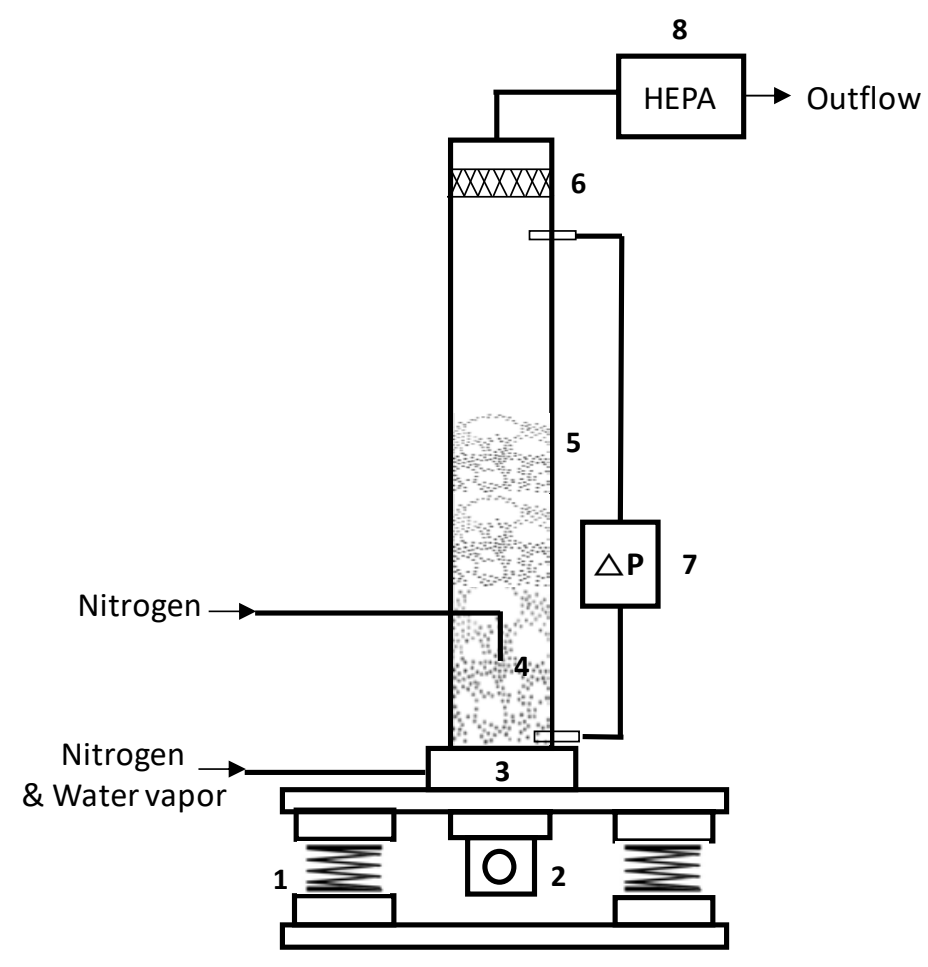

Figure 1: Schematic diagram of experimental setup. 1: Vibration isolator; 2: Magnetic vibrator; 3: Gas distributor; 4: Microjet; 5: Fluidization reactor; 6: Pre-filter; 7: Pressure manometer; 8: HEPA filter.

The electromagnetic vibrator was mounted below the wooden table that supported the column reactor. Vibration was controlled by a signal generator which provided vertical sinusoidal motions with controlled amplitude and frequency.

Dry nitrogen was supplied by a compressed nitrogen gas cylinder, and a mass flow controller (MFC) was used to regulate the gas flow rate through the bottom gas distributor. This flow was considered as the primary gas flow. The secondary gas flow passed through the downward pointing micro-sized nozzle at a height of about $10 \mathrm{~cm}$ above the distributor. 


\subsection{Materials}

The commercial nanopowder, $\mathrm{TiO}_{2} \mathrm{P} 25$, manufactured by Degussa Evonik was used for this work. The nanopowder was sieved using a $500 \mu \mathrm{m}$ sieve placed on a vibration shaker in order to remove large agglomerates that may have been gradually enlarged during packing, storage, and transportation. The properties of $\mathrm{TiO}_{2} \mathrm{P} 25$ are: primary particle size $21 \mathrm{~nm}$, surface area $50 \mathrm{~m}^{2} / \mathrm{g}$ and tap density $130 \mathrm{~kg} / \mathrm{m}^{3}[6]$.

\subsection{Operating conditions}

Nanosized powder was fluidized with nitrogen gas at a superficial velocity range from 0.005 to $0.035 \mathrm{~m} / \mathrm{s}$, supplied to the fluidized bed through a gas distributor at the bottom of the reactor. The resonance frequency of $50 \mathrm{~Hz}$ and vibrational amplitude were monitored using a vibration meter attached to the reactor. The vibrator was turned on before the microjet was started in order to avoid large bubble and channel formation. The fluidization behaviour was investigated by increasing the superficial gas velocity in small steps $(0.2 \mathrm{~cm} / \mathrm{s})$, starting from $0.5 \mathrm{~cm} / \mathrm{s}$. Additional experimental conditions appear in Table 1 .

Table 1: Experimental condition.

\begin{tabular}{|l|c|}
\hline Powder mass $(\mathrm{g})$ & 50 \\
\hline Vibrational frequency $(\mathrm{Hz})$ & 50 \\
\hline Vibrational intensity & $1,1.2,1.4,1.6,1.8,2$ \\
\hline Superficial gas velocity $(\mathrm{m} / \mathrm{s})$ & $0.005-0.033$ \\
\hline Microjet upstream pressure $(\mathrm{kPa})$ & $135.8,170.3,204.7,239.2,273.7,308.2$ \\
\hline
\end{tabular}

\section{RESULTS AND DISCUSSION}

\subsection{Bed expansion behavior}

Fig. 2 shows the variation in nondimensional height $\left(\mathrm{H} / \mathrm{H}_{0}\right)$ as a function of the gas velocity for the VFB and MVA fluidization systems. The nondimensional heights are obtained by dividing the fluidized bed height, $\mathrm{H}$ by the initial bed height, $\mathrm{H}_{0}(=0.12 \mathrm{~m})$. The MVA system's nondimensional height was 5 when gas velocity reached $0.02 \mathrm{~m} / \mathrm{s}$, which is a larger nondimensional height as compared to the VFB system's nondimensional height of 2.5. In both cases, the fluidized bed height increased as the gas velocity increased.

The Richardson and Zaki equation (shown in eqn (1) [7]) correlates the superficial gas velocity and the void fraction of the fluidized bed, and our results have been shown to be consistent with the trend that the fluidized bed expands uniformly as the superficial gas velocity is increased

$$
\mathrm{U}_{\mathrm{g}}=\mathrm{U}_{\mathrm{pt}} \varepsilon_{\mathrm{g}}{ }^{\mathrm{n}},
$$

where $U_{g}=$ superficial gas velocity; $U_{p t}=$ terminal velocity; $\varepsilon_{\mathrm{g}}=$ void fraction of fluidized bed; $\mathrm{n}=$ Richardson and Zaki exponent.

Eqn (2) shows the overall mass balance of the powder in the bed where $\rho_{\mathrm{a}}$ and $\varepsilon_{\mathrm{g}}$ indicate the bulk density of the powder and the void fraction of fluidized bed, and $\rho_{\mathrm{a} 0}$ and $\varepsilon_{\mathrm{g} 0}$ indicate the initial powder density and the initial void fraction of fluidized bed, respectively. The density of the powder does not vary under the experimental conditions imposed by the gas flow and the additional vibration [8]. Thus, eqn (3) applies 


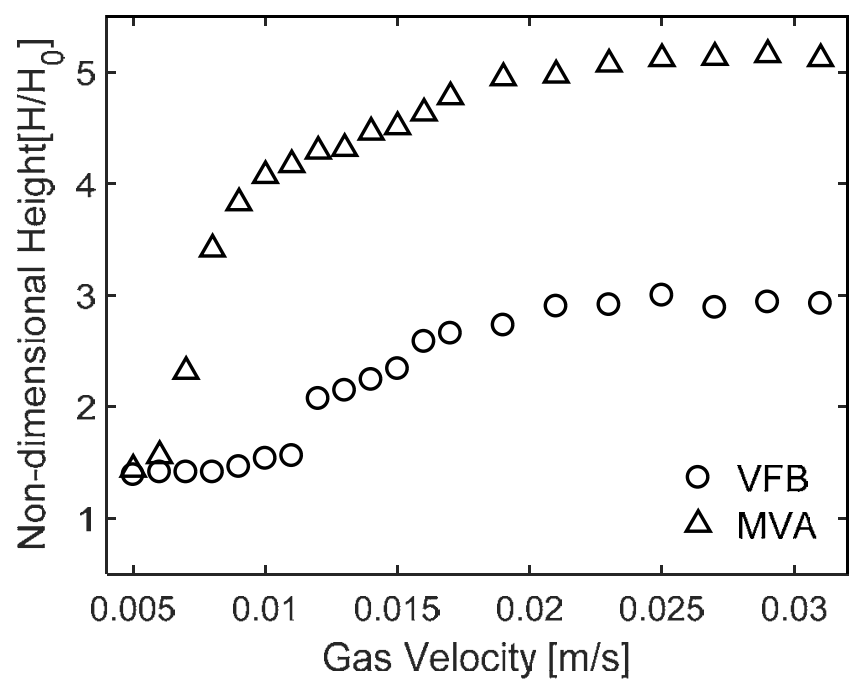

Figure 2: Nondimensional height of $\mathrm{TiO}_{2} \mathrm{P} 25$ as a function of superficial gas velocity.

$$
\rho_{\mathrm{a}}\left(1-\varepsilon_{\mathrm{g}}\right) \mathrm{HA}=\rho_{\mathrm{a} 0}\left(1-\varepsilon_{\mathrm{g} 0}\right) \mathrm{H}_{0} \mathrm{~A},
$$

where $\rho_{\mathrm{a}}=$ density of agglomerate; $\rho_{\mathrm{a} 0}=$ initial density of agglomerate; $\varepsilon_{\mathrm{g} 0}=$ void fraction of packed bed; $\mathrm{A}=$ cross sectional area of column

$$
\rho_{\mathrm{a}}=\rho_{\mathrm{a} 0} .
$$

Eqns (2) and (3) can be combined to generate eqn (4), which shows that the void fraction of the fluidized bed can be calculated from the nondimensional height and initial void fraction of the packed bed

$$
\varepsilon_{\mathrm{g}}=1-\left(\mathrm{H}_{0} / \mathrm{H}\right)\left(1-\varepsilon_{\mathrm{g} 0}\right) .
$$

The relationship between $\mathrm{U}_{\mathrm{g}}$ and $\varepsilon_{\mathrm{g}}$, eqn (1) can be written as a linear equation (eqn (5))

$$
\ln U_{\mathrm{g}}=\ln \mathrm{U}_{\mathrm{pt}}+\mathrm{n} \ln \varepsilon_{\mathrm{g}} \text {. }
$$

From the nondimensional height, we can simply calculate the void fraction of fluidized bed at each gas velocity using eqn (4). We used the gas velocity range up to $0.02 \mathrm{~m} / \mathrm{s}$ (i.e. before the plateau region) where nondimensional height is increasing continuously to be able to employ the Richardson and Zaki equation which describes the bed expansion as the gas flow is increased. Fig. 3 shows the data plotted according to eqn (5). The lines in Fig. 3 are the linear fits of the data points, and the slope represents the Richardson Zaki exponent " $n$ ", is an empirical parameter that can be directly related to $\mathrm{Re}_{t}$, the Reynolds number of the particle, under terminal settling conditions. Rowe [9] fitted their experimental data by the relation of $(4.7-n) /(n-2.35)=0.1 \operatorname{Re}_{t}^{3 / 4}$ and Garside and Al-Dibouni [10] proposed the empirical relation $(5.1-\mathrm{n}) /(\mathrm{n}-2.7)=0.1 \mathrm{Re}_{\mathrm{t}}{ }^{0.9}$.

In this work, we determined the exponent (n) values for $\mathrm{TiO}_{2}$ nanoparticle fluidization in the VFB and MVA system; these were 3.01 and 2.34, respectively. Kramer et al. [11] stated that the Richardson Zaki index, n, tends to approach 2.3 for the inertial regime and 4.6 for the viscous regime. Based on the values that were obtained, the MVA system is operating in the inertial regime, corresponding to high particle Reynolds number, suggesting that the 
MVA system has improved fluidization as compared to the VFB system. The MVA system resulted in a fluidized bed that expanded smoothly and was stabilized by a vibrational intensity of 1.6.

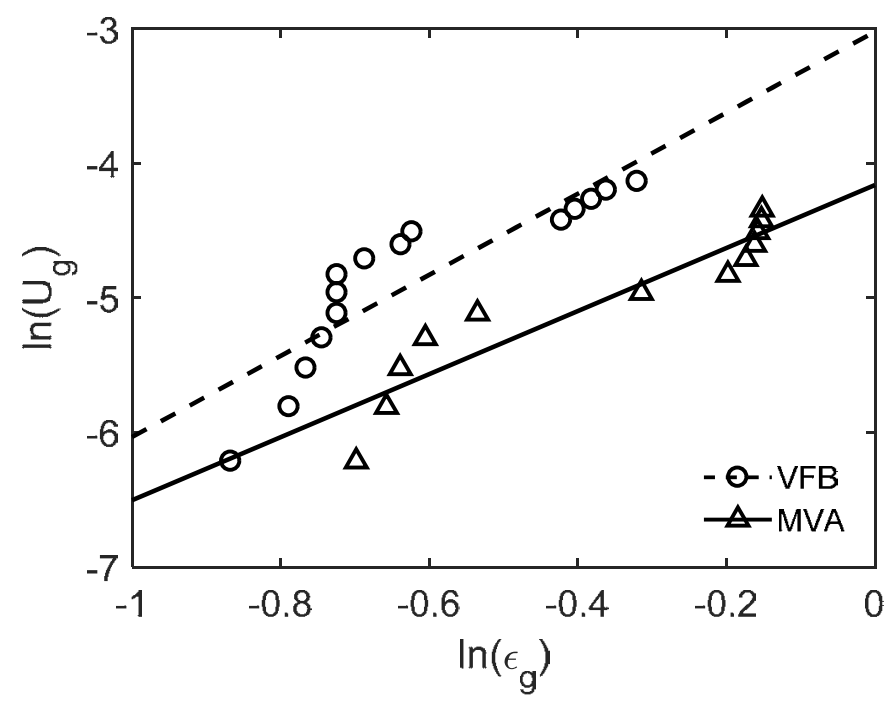

Figure 3: Logarithmic plot of superficial gas velocity against bed voidage derived theoretically. The points represent the theoretical data, while the lines are the linear fit.

\subsection{Influence of microjet}

In this work, the pressure upstream of the $500 \mu \mathrm{m}$ micronozzle was varied between 135.8 and $308.2 \mathrm{kPa}$ to show the influence of microjet assistance on the bed height. Theoretically, the flow through the micronozzle is said to be choked at pressures greater than $204.7 \mathrm{kPa}$ upstream, with a surrounding atmospheric pressure of $101.3 \mathrm{kPa}$. The resulting flow through the micronozzle becomes sonic if we assume adiabatic, frictionless, compressible flow of nitrogen [12]. We performed the experiments under the conditions as shown in Table 1 . The vibrational intensity, $\Gamma$, is a nondimensional value of the ratio of vibrational acceleration to gravitational acceleration, as indicated in eqn (6) [3]. The parameter $f$ is the frequency in $\mathrm{Hz}$, as set with the signal controller

$$
\Gamma=\left(\mathrm{Aw}^{2}\right) / \mathrm{g}
$$

where $\mathrm{A}=$ amplitude of vibration, as adjusted and measured by vibration meter; $\mathrm{w}=$ angular velocity, $\mathrm{w}=2 \pi \mathrm{f} ; \mathrm{f}=$ the frequency in $\mathrm{Hz} ; \mathrm{g}=$ gravitational acceleration, $9.8 \mathrm{~m} / \mathrm{s}^{2}$.

Fig. 4 shows the nondimensional height profile as a function of vibrational intensity at different upstream pressures of nitrogen that are fed into the micronozzle. When the gas velocity and the vibrational frequency were, respectively, $0.02 \mathrm{~m} / \mathrm{s}$ and 1.6 , the nondimensional height hit the maximum value. When the frequency was varied from the resonant frequency of $50 \mathrm{~Hz}$ to the antiresonant frequency of $60 \mathrm{~Hz}$, the non-dimensional bed height decreased. It should be noted that at higher pressures, variation in the bed height occurred due to the high flowrate from the microjet. This is illustrated in the error bars that 
are included with the data points in Fig. 4. The results indicate that the MVA system achieved higher nondimensional heights using lower upstream pressures (and hence lower micronozzle flow rates). However, when the micronozzle flow was completely turned off, the nondimensional height went down to 2.5, as shown in Fig. 2. Quevedo et al. [4] employed a similarly sized micronozzle as in the current work, but employed an alcohol solution and a nitrogen gas pressure through the micronozzle of $239.2 \mathrm{kPa}$ (i.e. sonic flow conditions); they achieved stable fluidization with bed expansion of up to six times the original bed height. As seen in Fig. 4, in the MVA system, subsonic velocity through the micronozzle was sufficient to achieve fluidization (and preferred in terms of enhancing the bed expansion in the absence of alcohol support) due to the added vibrational assistance. This result is particularly significant in terms of enabling more applications that would benefit from nanoparticle fluidization but where relatively pristine chemical conditions are required.

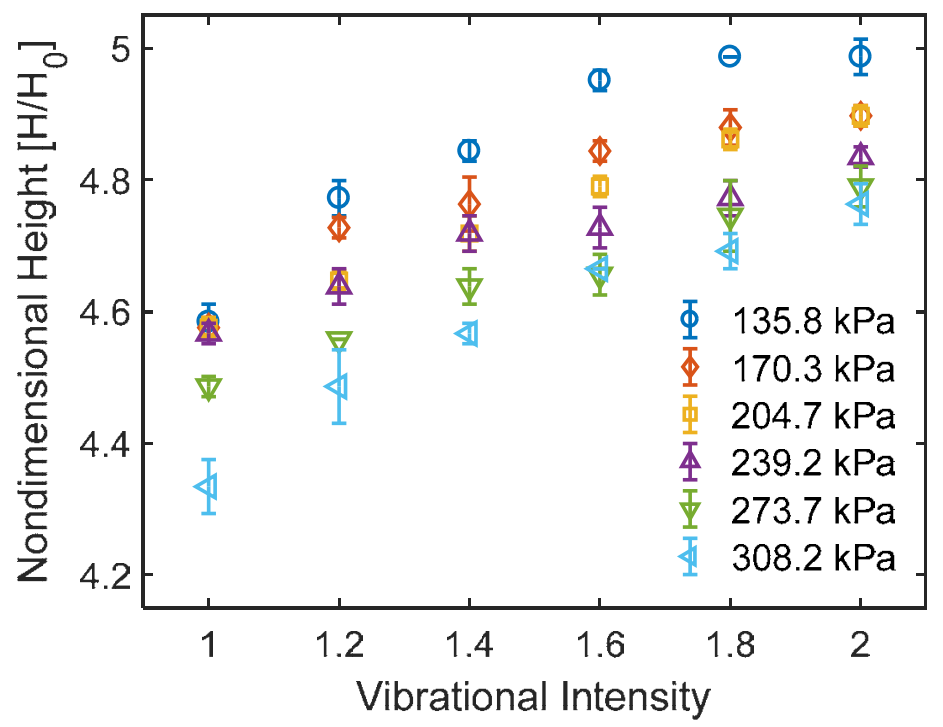

Figure 4: Nondimensional height as a function of vibrational intensity at different upstream pressures through the microjet (frequency: $50 \mathrm{~Hz}$ ).

\section{ACKNOWLEDGEMENT}

The authors gratefully acknowledge Arizona State University, Ira A. Fulton Schools of Engineering for research funding and graduate student support.

\section{REFERENCES}

[1] Wang, Y., Gu, G., Wei, F. \& Wu, J., Fluidization and agglomerate structure of $\mathrm{SiO}_{2}$ nanoparticles. Powder Technology, 124(1-2), pp. 152-159, 2002.

[2] Mawatari, Y., Ikegami, T., Tatemoto, Y. \& Noda, K., Prediction of agglomerate size for fine particles in a vibro-fluidized bed. J. Chem. Eng. Jpn., 36(3), pp. 277-283, 2013.

[3] Nam, C.H., Pfeffer, R., Dave, R.N. \& Sundaresan S., Aerated vibrofluidization of silica nanoparticles. AIChE J., 50(8), pp. 1776-1785, 2004. 
[4] Quevedo, J.A., Omosebi, A. \& Pfeffer, R., Fluidization enhancement of agglomerates of metal oxide nanopowders by microjets. AIChE J., 56(6), pp. 1456-1468, 2010.

[5] Richardson, J.F. \& Zaki, W.N., Sedimentation and fluidisation. Part 1. Trans. Inst. Chem. Eng., 32, pp. 35-53, 1954.

[6] Evonik Industries, AEROXIDE ${ }^{\circledR}, A E R O D I S P^{\circledR}$ and AEROPERL ${ }^{\circledR}$ Titanium Dioxide as Photocatalyst, pp. 5-6, 2018.

[7] Wang, H., Zhou, T., Yang, J.S., Wang, J.J., Hiroyuki, K. \& Mawatari, Y., Model for calculation of agglomerate sizes of nanoparticles in a vibro-fluidized bed. Chem. Eng. Technology, 33(3), pp. 388-394, 2010.

[8] Wang, Y., Gu, G., Wei, F. \& Wu, J., Fluidization and agglomerate structure of $\mathrm{SiO}_{2}$ nanoparticles. Powder Technology, 124, pp. 152-159, 2002.

[9] Rowe, P.N., A convenient empirical equation for estimation of the Richardson and Zaki exponent. Chem. Eng. Sci., 42(11), pp. 2795-2796, 1987.

[10] Garside, J. \& Al-Dibouni, M.R., Velocity-voidage relationships for fluidization and sedimentation in solid-liquid systems. Ind. Eng. Chem. Process Des. Develop., 16(2), pp. 206-214, 1977.

[11] Kramer, O.J.I., Mdeol, P.J. \& Van der Heok, J.P., Improvement of the RichardsonZaki liquid-solid fluidization model on the basis of hydraulics. Powder Technology, 343, pp. 465-478, 2019.

[12] Pope, S.B., Turbulent Flows: Free Shear Flows, Cambridge University Press: Cambridge, 2000. 